\title{
AFINAL, O QUE É VERDADE?
}

Luciane Weber Baia Hees

\begin{abstract}
Doutora em Psicologia da Educação pela PUC-SP; Mestre em Políticas e Gestão Educacional. Professora universitária e docente colaboradora no Curso de Mestrado Profissional em Educação do Centro Universitário Adventista de São Paulo Campus EC. E-mail: luciane.hees@gmail.com
\end{abstract}

Graduandos no curso de Direito pelo Centro Universitário Adventista de São Paulo/ UNASP - Campus EC. E-mail: anapaula.lima@unasp.edu.br; scarlet.paixao@unasp.edu.br; bruno.magalhaes@unasp.edu.br; jackeline.ribeiro@unasp.edu.br e michelly.lima@unasp.edu.br.

\section{RESUMO}

Este artigo aborda o tema da verdade, conceito fundamental na constituição do ser humano. O objetivo é discutir o surgimento da verdade, sua evolução histórica e as teorias da verdade predominantes ao longo de seu desenvolvimento. Sem tentar exaurir o assunto, visto que o tema exige um estudo aprofundado de vários fluxos filosóficos, utilizou-se da pesquisa bibliográfica, para através do método indutivo encontrar as principais correntes que explicam o que é a verdade. De natureza exploratória, esse estudo encontra-se no campo da filosofia e da pesquisa qualitativa. Conclui-se que a verdade é essencial para compreensão do ser humano e de suas relações, portanto é fundamentalmente eficaz na busca do ideal de justiça, nas decisões judiciais, para alcançar a coerência nas petições dos juristas e para aplicação das normas do ordenamento jurídico.

PALAVRAS-CHAVE: Verdade. Teorias da Verdade. Filosofia.

\section{SO, WHAT IS TRUTH?}

\begin{abstract}
This article addresses the theme of truth, a fundamental concept in the constitution of the human being. The purpose is to discuss the emergence of truth, its historical evolution, and the prevailing theories of truth throughout its
\end{abstract}


development. Without trying to exhaust the subject, since the subject requires an in-depth study of several philosophical flows, it was used of the bibliographical research, for through the inductive method to find the main currents that explain what the truth is. Of exploratory nature, this study is in the field of philosophy and qualitative research. It is concluded that truth is essential for understanding human beings and their relationships, so it is fundamentally effective in pursuing the ideal of justice, in judicial decisions, in order to achieve coherence in the petitions of jurists and for the application of legal norms.

KEYWORDS: Truth. Theories of Truth. Philosophy.

\section{IINTRODUÇÃO}

Pretende-se nesse artigo, discutir o surgimento da verdade, sua evolução histórica e as teorias da verdade predominantes ao longo de seu desenvolvimento. Resgatando significados e conceitos ao longo da história, encontramos em Platão e Aristóteles diferentes visões sobre verdade. Platão apresenta seus pressupostos sobre verdade através da "Alegoria da Caverna”, em sua principal obra chamada "República”, e Aristóteles fala sobre a verdade no livro “ Ida Metafisica”.

Como método, elencou-se a pesquisa bibliográfica. Trata-se de uma pesquisa qualitativa de natureza descritiva e encontra-se no campo da filosofia. Para o entendimento do tema proposto, faz-se necessária uma breve introdução ao surgimento da verdade, seguida dos principais conceitos e origem etimológica da palavra verdade. Posteriormente, apresenta-se a evolução e o percurso da verdade na história descrito pela contribuição oferecida pelas principais Teorias da Verdade.

\section{ORIGEM E CONCEPÇÕES DA VERDADE}

A busca da verdade sempre constituiu um dos problemas fundamentais da filosofia. Então, o que significa a verdade para a Filosofia? Existem diferentes concepções sobre a natureza do conhecimento verdadeiro, entre elas ressalta-se as advindas das línguas grega, latina e hebraica, o quê, dependendo de qual das três ideias originais da verdade predomine, vai moldar e direcionar o conceito de verdade. Segundo Chauí (1998), se examinarmos essas diferentes concepções da verdade, observaremos que alguns aspectos fundamentais são preservados em todas elas:

1. compreender as causas da diferença entre o parecer e o ser das coisas ou dos erros; 
2. compreender as causas da existência e das formas de existência dos seres;

3. compreender os princípios necessários e universais do conhecimento racional;

4. compreender as causas e os princípios da transformação dos próprios conhecimentos;

5. separar preconceitos e hábitos do senso comum e a atitude crítica do conhecimento;

6. explicitar com todos os detalhes os procedimentos empregados para o conhecimento e os critérios de sua realização;

7. liberdade de pensamento para investigar o sentido ou a significação da realidade que nos circunda e da qual fazemos parte;

8. comunicabilidade, isto é, os critérios, os princípios, os procedimentos, os percursos realizados, os resultados obtidos devem poder ser conhecidos e compreendidos por todos os seres racionais. Como escreve o filósofo Espinosa, o Bem Verdadeiro é aquele capaz de comunicar-se a todos e ser compartilhado por todos;

9. transmissibilidade, isto é, os critérios, princípios, procedimentos, percursos e resultados do conhecimento devem poder ser ensinados e discutidos em público. Como diz Kant, temos o direito ao uso público da razão;

10. veracidade, isto é, o conhecimento não pode ser ideologia, ou, em outras palavras, não pode ser máscara e véu para dissimular e ocultar a realidade servindo aos interesses da exploração e da dominação entre os homens. Assim como a verdade exige a liberdade de pensamento para o conhecimento, também exige que seus frutos propiciem a liberdade de todos e a emancipação de todos;

11. a verdade deve ser objetiva, isto é, deve ser compreendida e aceita universal e necessariamente, sem que isso signifique que ela seja "neutra" ou "imparcial", pois o sujeito do conhecimento está vitalmente envolvido na atividade do conhecimento e o conhecimento adquirido pode resultar em mudanças que afetem a realidade natural, social e cultural (CHAUÍ, 1998, p.133)

Portanto, existe uma espécie de relativismo entre as diferentes concepções sobre a natureza da verdade, que conversam entre si por meio desses aspectos preservados. Mas, afinal, o que é a verdade? Inicialmente, para conceituar "verdade" recorremos à alguns dicionários de filosofia que explicam a verdade da seguinte maneira:

Verdade (lat. veritas) 1. Classicamente, a verdade se define como adequação do intelecto ao real. Pode-se dizer, portanto, que a verdade é uma propriedade dos juízos, que podem ser verdadeiros ou falsos, dependendo da correspondência entre o que afirmam ou negam e a realidade de que falam (MARCONDES; JAPIASSÚ, 2001, on-line)

Contextualizando no mundo ocidental, o conceito de verdade está relacionado com a herança do grego, do latim e do hebraico. 
Aletheia, assim é denominada a verdade em grego. Nesse contexto, estamos nos referindo ao não-oculto ou ao que não está dissimulado. Aletheia é o oposto de pseudos (escondido, dissimulado). Segundo os gregos, nesse caso, o que importa é que "olho" e "espírito", quando estão vendo o verdadeiro, estão diante de algo evidente próprio das coisas.

Portanto, a verdade está nas coisas. "Dizer a verdade é dizer a verdade do que está na realidade manifestada, e não na realidade que não se manifesta, oculta, a que engana" (GUIRALDELLI, 2001, p.2).

Em latim, verdade é veritas, que se refere à exatidão de um relato, não uma qualidade das coisas, mas do quanto um relato é exato. Nesse caso, estamos unicamente no campo da linguagem, e um relato é verdadeiro se anunciar pormenorizadamente e exatamente os fatos reais (GUIRALDELLI, 2001).

E por fim, mas não menos importante, em hebraico verdade se relaciona com emunah. Essa palavra refere-se ao que foi pactuado, para o presente ou para o futuro. "Trata-se de uma palavra que tem a ver com a esperança, com a confiança, com a ideia de que o que se combinou (...)vai mesmo acontecer. (...)tem a ver com o pacto histórico, político, (...) mas tem a ver também com a profecia" (GUIRALDELLI, 2001).

No Dicionário de Filosofia, Abbagnano (1982) explica a verdade da seguinte forma:

Validade ou eficácia dos procedimentos cognoscitivos. Em geral, entende-se por Verdade a qualidade em virtude da qual um procedimento cognoscitivo qualquer torna-se eficaz ou obtém êxito. Essa caracterização pode ser aplicada tanto às concepções segundo as quais o conhecimento é um processo mental quanto às que o consideram um processo linguístico ou semiótico. Ademais, tem a vantagem de prescindir da distinção entre definição de Verdade e critério de Verdade. Essa distinção nem sempre é feita, nem é frequente; quando feita, representa apenas a admissão de duas definições de Verdade (ABBAGNANO, 1982, p.994).

A verdade é a concordância entre o sentido e a realidade, entre os argumentos e a verificação da existência sólida dos elementos que sustenta a argumentação. (CARNEIRO, 2016).

Dando sequência, não poderíamos deixar de citar o Filosofo Nietzsche, segundo ele os homens constroem suas histórias em fundamentações capazes de produzir uma verdade para a moral sobre o ser justo ou não. Nietzsche, no decorrer do tempo, busca a explicação para obter respostas de como e quais os passos que o ser humano foi capaz de prosseguir para chegar em determinada conclusão. Para ele, a verdade não é absoluta, entretanto é capaz de Complexitas - Rev. Fil. Tem., Belém, v. 3, n. 2, p. 29-39, jul./dec. 2018 - ISSN: 2525-4154 
esclarecer e justificar valores impostos e particulares (CAMARGO, 2018).

A verdade possui dupla interpretação, ou seja, passaremos a enxerga-la se entendermos os dois sentidos de "verdade". Para a "exposição da verdade" (Darstellung der Wahrheit) objetiva-se, em primeiro lugar, mostrar a exposição do conteúdo e, em segundo lugar, a forma na qual se baseia a própria verdade. Esses dois momentos precisam um do outro para o entendimento completo da verdade (GAGNEBIN, 2005).

Apesar dos diversos conceitos sobre verdade, existem basicamente duas concepções principais: Para Platão, a verdade se aplica primeiro ao objeto e depois ao enunciado; já para Aristóteles, a verdade está ligada ao ato de dizer e, dessa forma, não existe verdade sem enunciado, mas este não basta em si mesmo como verdade.

Na obra "República", é narrada uma alegoria por Platão acerca de alguns prisioneiros que estavam em uma caverna, totalmente amarrados, tendo acesso somente às sombras que eram projetadas pela claridade da luz da fogueira. Contudo, como já havia acostumado com essa situação, acreditava-se que isso era a realidade. Certa vez, um prisioneiro ousou sair da caverna, e descobriu como era maravilhoso o lado de fora, voltou para contar a novidade para seus antigos companheiros, entretanto não foi compreendido. Por esse motivo, estes prisioneiros resolveram nunca saírem da caverna, por temer o que tinha do lado de fora.

Segundo Heidegger, a interpretação da alegoria platônica é considerada uma "doutrina da verdade" na qual é demostra a essência da verdade.

[...] a "alegoria da caverna" ilustra a essência da "formação". Em contrapartida, a interpretação da "alegoria" que agora tentaremos, deve apontar para a "doutrina" platônica sobre a verdade. Não se sobrecarrega, desse modo, a "alegoria", com algo que lhe é estranho? A exegese ameaça degenerar em uma violenta reinterpretação. Deixemos que assim pareça, até que se tenha firmado a compreensão de que o pensamento de Platão se submete a uma mudança na essência da verdade, que se transforma na lei oculta para o que o pensador diz. Em concordância com a interpretação exigida por uma aflição futura, a "alegoria" não ilustra apenas a essência da formação, mas permite, ao mesmo tempo, a apreensão de uma transformação essencial da "verdade". Mas, então, se a "alegoria" quer mostrar os dois, não será necessário que uma relação essencial entre a "formação" e a "verdade" predomine? De fato, essa relação subsiste. Subsiste, porque a essência da verdade e o modo de sua transformação é que tornam possível a "formação" em sua estrutura fundamental (DRUCKER, C.; GOLLNICK, S, 2013, pp.6-7).

Já Aristóteles afirma que não é possível haver verdade sem enunciado uma vez que é 
através do enunciado que, então, haverá algo que se discuta e seja base para a afirmação. Aristóteles, por sua vez, se aproximou da lógica e, desde então, essa relação foi conhecida como coisa (SÓ FILOSOFIA, 2018). Segundo Aristóteles, existem dois teoremas fundamentais: o primeiro deles é de que a verdade estaria no pensamento ou na linguagem, e não no objeto; o segundo é de que a medida da verdade estaria presente no objeto, na ação. Partindo dessas concepções, estabelece-se as Teorias da Verdade.

\section{TEORIAS DA VERDADE}

Além dos conceitos de verdade, é relevante discutirmos as teorias da verdade para entendermos sua origem e a evolução da verdade ao longo do tempo.

As teorias da verdade podem ser divididas em duas classes: as teorias tradicionais de verdade (teorias substantivas de verdade) e as teorias minimalistas de verdade (BLACKBURN; SIMMONS, 1999).

\subsection{TEORIAS TRADICIONAIS OU SUBSTANTIVAS}

Descrevendo primeiramente as teorias tradicionais da verdade citamos basicamente quatro: a teoria da correspondência, a teoria da coerência, a teoria pragmatista e a teoria da verificação ideal (Ghiraldelli Jr., P., 2000).

Considerando que $\mathrm{X}$ é uma frase, uma declaração, um pensamento ou uma proposição (a discussão sobre isso iria longe, e aqui, por razões de tempo, eu vou eliminar essa parte, que pode ser encontrada em Theories of Truth (Kirkham, 1995)), e que o símbolo sse (iff) é o "se e somente se", então essas quatro teorias podem ser expressas assim:

Teoria da Correspondência: $\mathrm{X}$ é verdadeiro sse $\mathrm{X}$ corresponde a um fato;

Teoria da Coerência: $X$ é verdadeiro sse $X$ é um membro de um conjunto de crenças coerente internamente;

Teoria Pragmatista: $\mathrm{X}$ é verdadeiro sse $\mathrm{X}$ é útil de se acreditar;

Teoria da Verificação Ideal: $\mathrm{X}$ é verdadeiro sse $\mathrm{X}$ é provável, ou verificável em condições ideais (GUIRALDELLI, 2001, p.3).

A teoria da correspondência tem origem na afirmação de Aristóteles: "dizer do que é que ele é, ou dizer do que não é que ele não é, é a verdade". Ou seja: "X é verdadeiro se e somente se X corresponde a um fato". Entretanto, segundo Guiraldelli (2001) explica, estamos comparando coisas heterogêneas, ou seja, de um lado algo que é uma expressão, uma frase, e de outro lado o fato. Por isso, estamos comparando coisas heterogenias: linguística X 
fato. Essa teoria funciona razoavelmente bem para fatos positivos, mas isso não funciona para fatos negativos, por exemplo:

Se digo: "há um urso dentro desta sala em que estamos", então temos um fato. O fato é: há um urso dentro desta sala. Se aplicarmos a fórmula da teoria da correspondência temos: ",há um urso dentro desta sala"e se e somente se há um urso dentro desta sala". O enunciado $X$,há um urso dentro desta sala"e corresponde ao fato há um urso dentro desta sala. Mas vejamos se a teoria da correspondência funciona com fatos negativos, por exemplo. Eu digo: "não há um urso dentro desta sala". Nossa equação fica o seguinte: "não há um urso dentro desta sala" é verdadeiro se e somente se não há um urso dentro dessa sala". Ora, aparentemente a coisa é a mesma, mas se olharmos mais de perto, não é. Pois, afinal, o fato há um urso dentro desta sala me informa diretamente algo, o que legitimaria a correspondência entre fato e enunciado. Mas não há um urso dentro desta sala me informa o que, afinal? Qual é o fato, nesse caso? Estou dizendo que há cadeiras na sala e não um urso? Estou dizendo que só há cadeiras na sala cheia de elefantes? Estou dizendo que há gente e não urso? Estou dizendo que tenho uma sala completamente sem móveis, sem gente e sem urso? Ou simplesmente estou dizendo que esta sala é uma Arca de Noé mas esqueceram do urso? Em outras palavras, quando tenho algo que seria um fato negativo, como dizer que $X$ corresponde a um fato, como quer a teoria correspondentista? A que fato a expressão linguística "não há um urso dentro desta sala" corresponde? Não sabemos (GUIRALDELLI, 2001, p.4).

Diante disso, nos reportamos à teoria da coerência que afirma que isso não tem sentido e que, nos enunciados, as coisas devem ser comparadas com coisas, crenças com crenças etc. Ou seja, um sistema de crenças é considerado verdadeiro quando seus elementos são coerentes uns com os outros. A verdade é a propriedade de se pertencer a um sistema coerente de crenças ou enunciados. Entretanto:

(...) o que se faz contra o coerentismo é dizer que conhecemos vários conjuntos harmoniosos de crenças muito bem estruturados, mas que nós não estaríamos dispostos a gastar uma gota de saliva em favor deles em uma discussão. São coerentes, mas nós não temos a coragem de chamá-los de verdadeiros, porque em nada eles nos convencem de falar de alguma realidade. Se o coerentismo abre a guarda para o relativismo, ele não seria uma solução para as falhas do correspondentismo, pois no limite ele tece o tapete do ceticismo. Ora, o ceticismo é exatamente a figura contra a qual a filosofia tem sua guerra permanente, dado que o cético, grosso modo, é o que fala sobre a impossibilidade do conhecimento verdadeiro (GUIRALDELLI, 2001, p.6).

Segundo Marcondes e Japiassú (2001), a teoria da verdade como coerência considera a 
verdade como resultando de sua coerência com um sistema de crenças ou verdades determinadas anteriormente. Dessa forma, estaria sendo preservada a ausência de contradição dentro do sistema.

Foi contra a abertura da teoria da coerência diante do relativismo e do ceticismo que James e Dewey introduziram a teoria pragmatista da verdade. Segundo Marcondes e Japiassú (2001), nesse caso, a verdade resulta do consenso entre o que é considerado aceitável diante do real. Essa corrente filosófica é norte-americana, difundida no final do século XIX. A verdade no pragmatismo é aquilo que serve de solução imediata aos problemas, mas não se prende a um sistema moral normativo; O que se toma como verdadeiro é o agir humano segundo objetivos práticos (Araújo, 2009).

Não há nada de novo absolutamente no método pragmático. Sócrates foi adepto dele. Aristóteles empregou-o metodicamente. Locke, Berkeley e Hume fizeram pequenas contribuições à verdade por seu intermédio. Shadworth Hodgson insiste em que realidades são somente o que sabemos delas. Esses precursores do pragmatismo, porém, usaram-no de maneira fragmentária: apenas o preludiaram. Não foi senão em nossa época que se generalizou, tornou-se consciente de uma missão universal, aspirou a um destino conquistador. Acredito nesse destino, e espero poder terminar transmitindo-lhes toda a minha fé (JAMES, 1989, p.19).

Para os pragmatistas a verdade tem de ser tão somente útil e satisfatória, correspondendo com os meios que condicionam o pensamento. Ou seja, o pragmatismo tem como característica epistemológica o empirismo.

Por fim, para a teoria da verificação ideal, em parte pragmatista, a verdade da proposição se estabelece a partir de seus resultados, ou seja, de sua aplicação prática e de sua verificação pela experiência (MARCONDES; JAPIASSÚ, 2001). No caso desta teoria, o "X" será verdadeiro somente se " $\mathrm{X}$ " for verificável em condições ideais.

Para Dummett, na teoria da verificação ideal a verdade é subordinada a nossa capacidade de descobri-la, ela é entendida como o resultado do processo de verificação (real ou possível). Portanto, um enunciado somente será verdadeiro se for possível ter acesso epistêmico a sua verdade.

\subsection{TEORIAS MINIMALISTAS}

As teorias minimalistas são compostas pela teoria deflacionista, a teoria da redundância e a teoria semântica e todas elas estão dentro do campo semântico. 
Na teoria deflacionista os filósofos desmembram a verdade e tiram dela toda a carga metafisica nela implícita. "O filósofo deflacionista diz que a verdade não é uma propriedade "real", ou "robusta", ou uma propriedade metafisicamente interessante". (GUIRALDELLI, 2001, p.9)

Para os deflacionistas, em uma frase, a palavra "verdade" é apenas um item de performance que tem o objetivo de auxiliar a frase e as deixar mais completa, por essa razão a verdade não pertence ao campo metafisico". (GUIRALDELLI, 2001, p.9).

Para teoria da redundância, a verdade não é uma propriedade substancial, simplesmente porque não é uma verdade. O teórico da redundância sustenta que a expressão "é verdade" é redundante. Ou seja, quando afirmamos que " Marina é jornalista" ou "É verdade que Marina é jornalista" a expressão "é verdade” é redundante.

A teoria semântica afirma que a verdade é uma propriedade das sentenças. Essa teoria foi feita sobre um caráter lógico da preposição. Esta, para ter significado, é preciso que seja passível das atribuições de verdadeiro ou falso, segundo critérios analíticos ou empíricos. (GUIRALDELLI, 2001, p.10)

\section{CONSIDERAÇÕES FINAIS}

Buscou-se nesse breve estudo discorrer sobre o surgimento da verdade, sua evolução histórica e algumas das concepções filosóficas predominantes ao longo de seu desenvolvimento que compuseram as teorias da verdade.

Concluímos que existem diferentes conceitos sobre o que é verdade. Diversos autores, estudiosos e filósofos apresentam distintas visões, dentre esses, destacam-se os conceitos de Platão e Aristóteles. Para Platão, a verdade se aplica primeiro ao objeto e depois ao enunciado e, para Aristóteles, a verdade está ligada ao ato de dizer. Aristóteles explica a verdade através das teorias tradicionais de verdade, a saber: a teoria da correspondência, a teoria da coerência e a teoria da verificação ideal. Em cada uma delas, explica a verdade com um enfoque e função diferente. Segundo Aristóteles a teoria da correspondência é dizer do que é que ele é, ou não dizer do que é que ele não é, é a verdade. Já a teoria da coerência afirma que não tem sentido, e que nos enunciados as coisas devem ser comparadas com coisas e crenças.

Constatou-se, pelo teor dos conteúdos abordados que as teorias tradicionais ainda são defendidas, mas atualmente se adotam, na maior parte das vezes, as teorias minimalistas. 
Quando se fala no minimalismo, faz-se referência ao que é detalhado, pois o ser humano sempre busca os pequenos (mínimos) detalhes para expor seu ponto de vista, o que leva à prática constante da teoria minimalista. As teorias minimalistas são todas do campo semântico, mas elas se diferem entre si ora por passos bem visíveis ora por sutilezas só perceptíveis para quem tem uma formação filosófica, técnica, nas áreas de lógica, semântica e, enfim, filosofia da linguagem.

Conclui-se que a verdade é essencial para compreensão do ser humano e de suas relações. Portanto, é fundamental na busca da justiça, nas decisões judiciais, para alcançar a coerência nas petições dos juristas e para aplicação das normas do ordenamento jurídico.

\section{REFERÊNCIAS BIBLIOGRÁFICAS}

ABBAGNANO, Nicola. Dicionário de filosofia. 2. ed. São Paulo: Mestre Jou, 1982.

ARAUJO, A. M. Das nuances $e$ estruturas da Teoria acerca da Verdade Pragmática de Willian James. 2009. Disponível em: http://www.consciencia.org/dasnuances-e-estruturas-da-teoria-acercada-verdade-pragmatica-de-willianjames. Acesso em out 2018.

BLACKBURN, S.; SIMMONS. Truth. Oxford: Oxford University Press, 1999.

CAMARGO, Gustavo Arantes. Sobre o conceito de verdade em Nietzsche. Revista Trágica: estudos sobre Nietzsche. Rio de Janeiro, v. 1, n. 2, p. 93-112, 2008.

CARNEIRO, Maria. Lógica e direito: a essencialidade das relações. Disponível em:

revistathemis.tjce.jus.br/index.php/TH EMIS/article/download/274/263.

Acesso em out 2018.

CHAUI, M. Convite à filosofia. 10. ed. São Paulo: Ática, 1998.
Universidade Federal do Rio Grande do Norte, Brasil.

DRUCKER, C.; GOLLNICK, S. A doutrina de Platão sobre a verdade. 2013. Disponível em: http://www.imagomundi.com.br/filo/h eidegger verdade.pdf. Acesso em: out. 2018.

DUMMETT, M. (1978) Truth and Other Enigmas, Harvard University Press.

CHAUÍ, Marilena. Convite á Filosofia. 13. ed. São Paulo: Ártica, 2008.

GAGNEBIN, Jeanne-Marie. Do conceito de Darstellung em Walter Benjamin ou verdade e beleza. Kriterion: Revista de Filosofia, v. 46, n. 112, p. 183-190, 2005.

GUIRALDELLI, P. Teorias $d a$ Verdade. Disponível em: http://www2.unifap.br/borges/files/20 11/02/Teorias-de-VerdadeBrev\%C3\%ADssima-Introdução.pdf. 2001. Acesso em out 2018.

Educação e ensino - perspectivas neopragmáticas. Ijuí: Unijui, 2000. 
JAMES, Willian. Pragmatismo. Coleção Os Pensadores. Nova cultural. São Paulo, SP. 1989.

MARCONDES, D.; JAPIASSÚ, H.. Dicionário Básico de Filosofia. Disponível em:

http://raycydio.yolasite.com/resources /dicionario de filosofia japiassu.pdf. Acesso em Out de 2018.

SÓ FILOSOFIA. Dicionário de Filosofia. Disponível em: http://www.filosofia.com.br/dicionari o.php. Acesso em out 2018.

HESS, L. W. B., LIMA, A. P., MAGAlhãeS, B. A., RIBEIRO, J. A., PAIXÃO, M., PAIXÃO, S. C. L. Afinal, O Que é Verdade? Complexitas - Rev. Fil. Tem. Belém, v. 3, n. 2, p. 29-39, jul./dec. 2018. Disponível em: http://www.periodicos.ufpa.br/index.php/complexitas/article/view/6585>. Acesso em: 05 de agosto de 2019. 